\title{
Acetaminophen (Paracetamol) Induces Hypothermia During Acute Cold Stress
}

\author{
Josh Foster ${ }^{1,2}$ (D) Alexis R. Mauger ${ }^{3} \cdot$ Andrew Govus $^{4} \cdot$ David Hewson $^{5} \cdot$ \\ Lee Taylor ${ }^{6,7}$
}

Published online: 1 August 2017

(c) Springer International Publishing AG 2017

\begin{abstract}
Background Acetaminophen is an over-the-counter drug used to treat pain and fever, but it has also been shown to reduce core temperature $\left(T_{\mathrm{c}}\right)$ in the absence of fever. However, this side effect is not well examined in humans, and it is unknown if the hypothermic response to acetaminophen is exacerbated with cold exposure.

Objective To address this question, we mapped the thermoregulatory responses to acetaminophen and placebo administration during exposure to acute cold $\left(10^{\circ} \mathrm{C}\right)$ and thermal neutrality $\left(25^{\circ} \mathrm{C}\right)$.
\end{abstract}

Josh Foster

j.foster2@1boro.ac.uk

1 Institute for Sport and Physical Activity Research, University of Bedfordshire, Bedford, UK

2 Environmental Ergonomics Research Centre, Loughborough University, Loughborough, UK

3 Endurance Research Group, School of Sport and Exercise Sciences, University of Kent, Chatham Maritime, UK

4 Department of Health Sciences, Swedish Winter Sports Research Centre, Mid Sweden University, Östersund, Sweden

5 Institute for Health Research, University of Bedfordshire, Luton, UK

6 ASPETAR, Qatar Orthopaedic and Sports Medicine Hospital, Athlete Health and Performance Research Centre, Aspire Zone, Doha, Qatar

7 School of Sport, Exercise and Health Sciences, Loughborough University, Loughborough, UK
Methods Nine healthy Caucasian males (aged 20-24 years) participated in the experiment. In a doubleblind, randomised, repeated measures design, participants were passively exposed to a thermo-neutral or cold environment for $120 \mathrm{~min}$, with administration of $20 \mathrm{mg} / \mathrm{kg}$ lean body mass acetaminophen or a placebo $5 \mathrm{~min}$ prior to exposure. $T_{\mathrm{c}}$, skin temperature $\left(T_{\mathrm{sk}}\right)$, heart rate, and thermal sensation were measured every $10 \mathrm{~min}$, and mean arterial pressure was recorded every $30 \mathrm{~min}$. Data were analysed using linear mixed effects models. Differences in thermal sensation were analysed using a cumulative link mixed model.

Results Acetaminophen had no effect on $T_{\mathrm{c}}$ in a thermoneutral environment, but significantly reduced $T_{\mathrm{c}}$ during cold exposure, compared with a placebo. $T_{\mathrm{c}}$ was lower in the acetaminophen compared with the placebo condition at each 10-min interval from 80 to 120 min into the trial (all $p<0.05)$. On average, $T_{\mathrm{c}}$ decreased by $0.42 \pm 0.13{ }^{\circ} \mathrm{C}$ from baseline after $120 \mathrm{~min}$ of cold exposure (range $0.16-0.57^{\circ} \mathrm{C}$ ), whereas there was no change in the placebo group $\left(0.01 \pm 0.1{ }^{\circ} \mathrm{C}\right) . T_{\mathrm{sk}}$, heart rate, thermal sensation, and mean arterial pressure were not different between conditions $(p>0.05)$.

Conclusion This preliminary trial suggests that acetaminophen-induced hypothermia is exacerbated during cold stress. Larger scale trials seem warranted to determine if acetaminophen administration is associated with an increased risk of accidental hypothermia, particularly in vulnerable populations such as frail elderly individuals. 


\section{Key Points}

Accidental hypothermia was the primary or secondary diagnosis in over 100,000 hospital admissions from 2005 to 2015 in the UK. In this study, we sought to determine whether acetaminophen, a non-prescription drug used to manage mild pain and fever, reduced core temperature stability during a 2-h passive cold or thermoneutral exposure.

Acetaminophen had no effect on core temperature in thermoneutral conditions compared with a placebo, but reduced core temperature by up to $0.57^{\circ} \mathrm{C}$ after $2 \mathrm{~h}$ of cold exposure. The present results improve our knowledge about the side effects of acetaminophen and provides important information of relevance for hypothermia pathology.

\section{Introduction}

Accidental hypothermia is characterised by an unintended core temperature $\left(T_{\mathrm{c}}\right)$ reduction to $35^{\circ} \mathrm{C}$ or lower. Such a fall in $T_{\mathrm{c}}$ can induce ventricular fibrillation and ultimately cardiac arrest if $T_{\mathrm{c}}$ declines to $<28{ }^{\circ} \mathrm{C}[1,2]$. In the USA, hypothermia was the cause or contributing cause of death in over 5500 cases between 2006 and 2010 [3], but this is likely underestimated since $T_{\mathrm{c}}$ needs to be measured at or near the time of death. Nonetheless, data from UK hospital episode statistics indicate that hypothermia was the primary or secondary diagnosis in over 100,000 hospital admissions from 2005 to 2015 [4]. Although death from hypothermia is rare, it remains a significant health risk in elderly and very young individuals, particularly during winter months and unaccustomed cold spells [1]. Interestingly, there is a growing body of evidence demonstrating that acetaminophen could reduce $T_{\mathrm{c}}$ stability during cold exposure (discussed below), placing users at an increased risk of accidental hypothermia.

Acetaminophen is an over-the-counter drug marketed as paracetamol in Europe and as Tylenol in the USA. It is best known for its ability to decrease pain perception and reduce $T_{\mathrm{c}}$ during a fever; each of these actions are in part mediated through an inhibition of cyclooxygenase (COX) enzyme activity [5]. However, there is evidence of a 'hypothermic' action of acetaminophen, which refers specifically to an acetaminophen-induced reduction in $T_{\mathrm{c}}$ independent of febrile status. In mice, high doses (150-300 mg/kg body mass) administered intravenously reduced $T_{\mathrm{c}}$ by $2-4{ }^{\circ} \mathrm{C}$ [6-8]. In humans, there have been 246 reports in Vigibase $\odot$ (the World Health Organization international database of adverse drug reactions) specific to acetaminophen-induced accidental hypothermia [9]. In addition, several case studies report profound hypothermia following therapeutic doses [10] and high doses of acetaminophen when ingested orally $[11,12]$. Finally, oral acetaminophen administration (20 mg/kg lean body mass) reduced $T_{\mathrm{c}}$ in young adults by $\sim 0.2{ }^{\circ} \mathrm{C}$ (range $0.10-0.39{ }^{\circ} \mathrm{C}$ ) during exposure to mild cold [13]. Although the $T_{\mathrm{c}}$ reductions were small, this hypothermic side effect of acetaminophen occurred in all 13 participants. Despite this data, additional criteria, such as the environmental temperature, are needed to accurately predict when acetaminophen poses the greatest risk for hypothermia development. Since the COX pathway could be involved in non-febrile thermogenesis [14, 15], inhibition of this enzyme by acetaminophen might cause $T_{\mathrm{c}}$ to fall during cold exposure, while exerting negligible effects on $T_{\mathrm{c}}$ while exposed to a warm environment.

If acetaminophen-induced hypothermia is a risk during cold exposure, this can have major implications for public health recommendations. Each year in the USA, 6\% of adults are prescribed acetaminophen at doses of more than $4 \mathrm{~g} /$ day [16], while it is also available over-the-counter without prescription. Acetaminophen is recommended as the first-line analgesic for the elderly because it has minimal drug interactions and is well tolerated when taken at recommended doses [17]. It is also recommended for use in neonatal intensive care units following minor procedures and circumcision [18, 19]. Each of these age groups has a high incidence of accidental hypothermia due to a decreased ability to produce heat and make perceptually driven behavioural changes [20,21]. Due to its hypothermic effects, use of acetaminophen in these populations could decrease their $T_{\mathrm{c}}$ to the point in which they are clinically hypothermic. However, the question remains as to whether acetaminophen exerts its hypothermic effect by increasing heat loss, or decreasing heat production. If the COX pathway is required for full heat production, inhibition of its activity by acetaminophen would cause $T_{\mathrm{c}}$ to fall during cold exposure while exerting no hypothermic action during a thermo-neutral exposure (in which no heat production is required).

The aim of this trial was to examine the thermoregulatory response to acetaminophen administration $(20 \mathrm{mg} /$ $\mathrm{kg}$ of lean body mass) during a 120-min exposure to a thermo-neutral and cold environment in healthy adult humans. Due to a potential role of COX in non-febrile thermogenesis $[14,15]$, it was hypothesised that acetaminophen would reduce $T_{\mathrm{c}}$ in cold conditions, but have no effect on $T_{\mathrm{c}}$ in thermo-neutral conditions relative to a placebo. 


\section{Methods}

\subsection{Ethics Approval}

Experimental procedures were approved by the University Research Ethics committee (approval code 2014ISPAR011). All experimental procedures conformed to the standards set by the World Association Declaration of Helsinki 'Ethical Principles for Research Involving Human Subjects'.

\subsection{Sample Size Calculation}

Power analyses were conducted with GPower software version 3.1 (Heinrich University, Düsseldorf, Germany) to determine the sample necessary to achieve two-tailed statistical significance $(\alpha=0.05)$, with a power of 0.90 and a partial eta-squared $\left(\eta^{2}\right)$ of 0.42 . Using $T_{\mathrm{c}}$ data from a previous experiment where acetaminophen was tested as a hypothermic agent [22], it was determined that nine participants were required to reach the statistical power. If acetaminophen exerts the hypothesised hypothermic response, a larger project within vulnerable populations may be warranted to determine if acetaminophen contributes to accidental hypothermia admissions.

\subsection{Participants}

Nine Caucasian males [age: $22 \pm 1$ years, height: $179 \pm 5 \mathrm{~cm}$, body mass: $80.7 \pm 11.9 \mathrm{~kg}$, body fat $(20 \pm 5 \%)$ ] volunteered to take part in this study. Participants were provided with written information regarding the experimental procedures, with supporting oral explanations from the principal investigator. All participants subsequently provided written informed consent. The participants were non-smokers, non-febrile (resting $T_{\mathrm{c}}<38{ }^{\circ} \mathrm{C}$ ), and free from musculoskeletal injury.

\subsection{Inclusion and Exclusion Criteria}

Prior to each laboratory visit, participants completed an alcohol use disorder identification test (AUDIT; [23]), a breathalyser test (AlcoSense, One, Berkshire, UK), and an acetaminophen risk assessment questionnaire. To avoid any risk of liver damage inflicted by acetaminophen, participants were not able to participate in the research if they scored above ten on the AUDIT questionnaire or alcohol was present in their bloodstream (i.e. $>0 \%$ blood alcohol content). In addition, the acetaminophen dose was relative to lean body mass, as it is a closer indicator of liver volume than total body mass [24]. No participants presented with any pre-existing medical conditions that may have put them at an increased risk of acetaminophen toxicity. Due to potential thermoregulatory adaptations [25, 26], individuals were not permitted to take part in any experimental procedures if they were heat/cold acclimated or acclimatised. Thus, those who had travelled to a hot/cold climate or participated in a laboratory based heat/cold acclimation protocol less than three weeks before the experiment, were not permitted to take part. All participants presented to the laboratory with a stable resting $T_{\mathrm{c}}$ of $36.5-37.5^{\circ} \mathrm{C}$.

\subsection{Experimental Design}

A schematic of the experimental design is displayed in Fig. 1. To determine if acetaminophen reduces $T_{\mathrm{c}}$ stability during cold stress compared to a placebo, the participants visited the laboratory on five occasions, each separated by at least seven days. On visit 1, participants arrived fasted (overnight) and their body fat was assessed via air
Fig. 1 Flowchart of the study design. Visits 2-5 completed in a randomised order for each participant. Visits separated by 1 week and drug administration double blinded

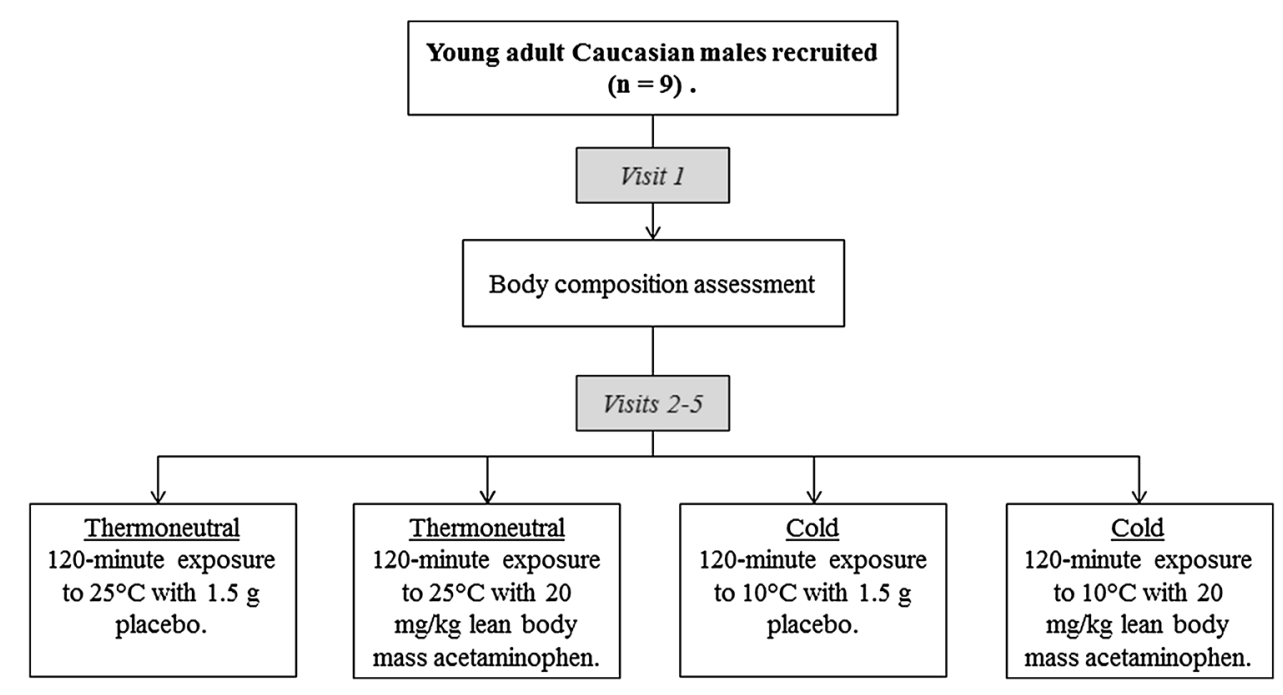


displacement plethysmography (Bod Pod, 2000A, Birmingham, UK). The body fat reading from this test was used to determine the participant's dose of acetaminophen received in the experimental trials. Visits 2-5 (experimental trials) were randomised (SPSS Inc., Chicago, USA), double blinded (drug only), and followed a repeated measures design. On these visits, participants were exposed to either cold $\left[10{ }^{\circ} \mathrm{C}, 40 \%\right.$ relative humidity (RH)] or thermoneutral $\left(25^{\circ} \mathrm{C}, 40 \% \mathrm{RH}\right)$ environmental temperatures for $120 \mathrm{~min}$, having been administered acetaminophen (20 mg/kg of lean body mass) or a placebo (dextrose). Acetaminophen (Paracetamol, Aspar Pharmaceuticals, London, UK) was administered via the oral route. The placebo was matched in terms of appearance, i.e. the same number of capsules were provided to the participants. The average dose of acetaminophen administered in the present work was $1287 \pm 173 \mathrm{mg}$ (range 1082-1486 mg).

\subsection{Experimental Protocol}

All participants arrived at the laboratory at 10:00. Upon arrival, participants were instrumented for the measurement of $T_{\mathrm{c}}$, skin temperature $\left(T_{\mathrm{sk}}\right)$, and heart rate (see Sect. 2.7 for details). Thirty minutes after arrival, participants consumed a standardised breakfast [cornflakes $(50 \mathrm{~g})$, milk $(250 \mathrm{~mL})$ and $1 \mathrm{~L}$ of tap water] and ingested acetaminophen or a placebo $1 \mathrm{~h}$ after the meal had been consumed. Participants remained rested in an upright, seated position between meal consumption and acetaminophen or placebo ingestion to ensure resting physiological status was attained. Participants were wheeled into the environmental chamber immediately following drug administration, and remained in the seated position for the duration of the protocol. Clothing was shorts and calf length socks, representing a Clo value of $\sim 0.1$ [One clo is defined as the amount of clothing required by a resting (sedentary) person to be indefinitely comfortable at ambient conditions where temperature is $21{ }^{\circ} \mathrm{C}$ ]. Resting measurements of $T_{\mathrm{c}}, T_{\mathrm{sk}}$, heart rate and thermal sensation were collected 5 min prior to acetaminophen and placebo ingestion, and subsequently every $10 \mathrm{~min}$ for $120 \mathrm{~min}$ ' post-ingestion. Blood pressure was measured prior to chamber entry and every $30 \mathrm{~min}$ (pre-ingestion, 30, 60, 90, 120 min post-ingestion) until the end of the trial. Data in Tables 1 and 2 provide the mean and range for each variable $\left[T_{\mathrm{c}}, T_{\mathrm{sk}}\right.$, heart rate, and mean arterial pressure (MAP)] at 30-min intervals.

\subsection{Instrumentation and Equations}

$T_{\mathrm{c}}$ was measured via insertion of a rectal thermistor (Henleys Medical Supplies, 400H/4491H, Hertfordshire, UK) $10 \mathrm{~cm}$ beyond the anal sphincter. The thermistor was connected via cable to a portable data logger (Libra
Medical, ET402, Birmingham, UK), in which $T_{\mathrm{c}}$ was continuously displayed throughout each experimental protocol. This was only visible to the researchers, not the participants.

Copper based thermocouples (Grant, EUS-U-VS5-0, Dorset, UK) connected to a wireless data logger (Grant, Squirrel Series, Dorset, UK) recorded $T_{\text {sk }}$ at four sites: calf, thigh, chest, and triceps [27]. Thermocouples were securely attached to the belly of each muscle by hypafix surgical adhesive tape (BSN medical, D-22771, Hamburg, Germany). The weighted $T_{\mathrm{sk}}$ of four sites was subsequently calculated using the equation below [27]:

Mean $T_{\text {sk }}=0.3 \times\left(T_{\text {arm }}+T_{\text {chest }}\right)+0.2 \times\left(T_{\text {calf }}+T_{\text {thigh }}\right)$

Thermal sensation was obtained using a 0-8 scale ranging from unbearably cold (0) to unbearably hot (8). Heart rate was measured during all tests using short-range telemetry (Polar, FS1, Warwick, UK), and was expressed as beats per minute $(\mathrm{b} / \mathrm{min})$.

Blood pressure was measured using a portable blood pressure monitor (Omron M5-1, Omron, Milton Keynes, UK). Measurements were taken at baseline (pre), and every $30 \mathrm{~min}$ of the 120-min exposure period. MAP was later calculated as $[(2 \times \mathrm{DBP})+\mathrm{SBP}] / 3 \mathrm{mmHg}$.

\subsection{Statistical Analysis}

All statistical analyses were performed using the 'nlme', 'ordinal', 'ez', 'sjPlot' and 'stats' packages in $R$ version 3.3.2. Normality assumptions were checked using quantile-quantile plots [28] and were plausible in all instances. Central tendency and dispersion are reported as means \pm standard deviation (SD). The Akaike information criteria (AIC) was used to determine model fit [29]. The correlation structure with the lowest AIC was chosen based on this procedure. A linear mixed model with fixed ('drug', 'time') and random ('subject id') effects was fitted with an autoregressive correlation structure (to account for autocorrelation) to examine the effect of acetaminophen on $T_{\mathrm{c}}, T_{\mathrm{sk}}$, and heart rate in thermo-neutral and cold conditions [time (13 levels): pre, 10, 20, 30, 40, $50,60,70,80,90,100,110,120 \mathrm{~min} \times$ drug (2 levels): placebo, acetaminophen]. The same model with different levels of time [time (5 levels): pre, 30, 60, 90, $120 \mathrm{~min}) \times$ drug (2 levels): placebo, acetaminophen] was fitted to determine the effect of acetaminophen on MAP in thermo-neutral and cold conditions. A cumulative link model was used to compare thermal sensation scores between placebo and acetaminophen in the thermo-neutral and cold conditions. The two-tailed alpha level of significance testing was set as $p \leq 0.05$. 95\% confidence intervals $(\mathrm{CI})$ are presented to denote the imprecision of the point estimate. 


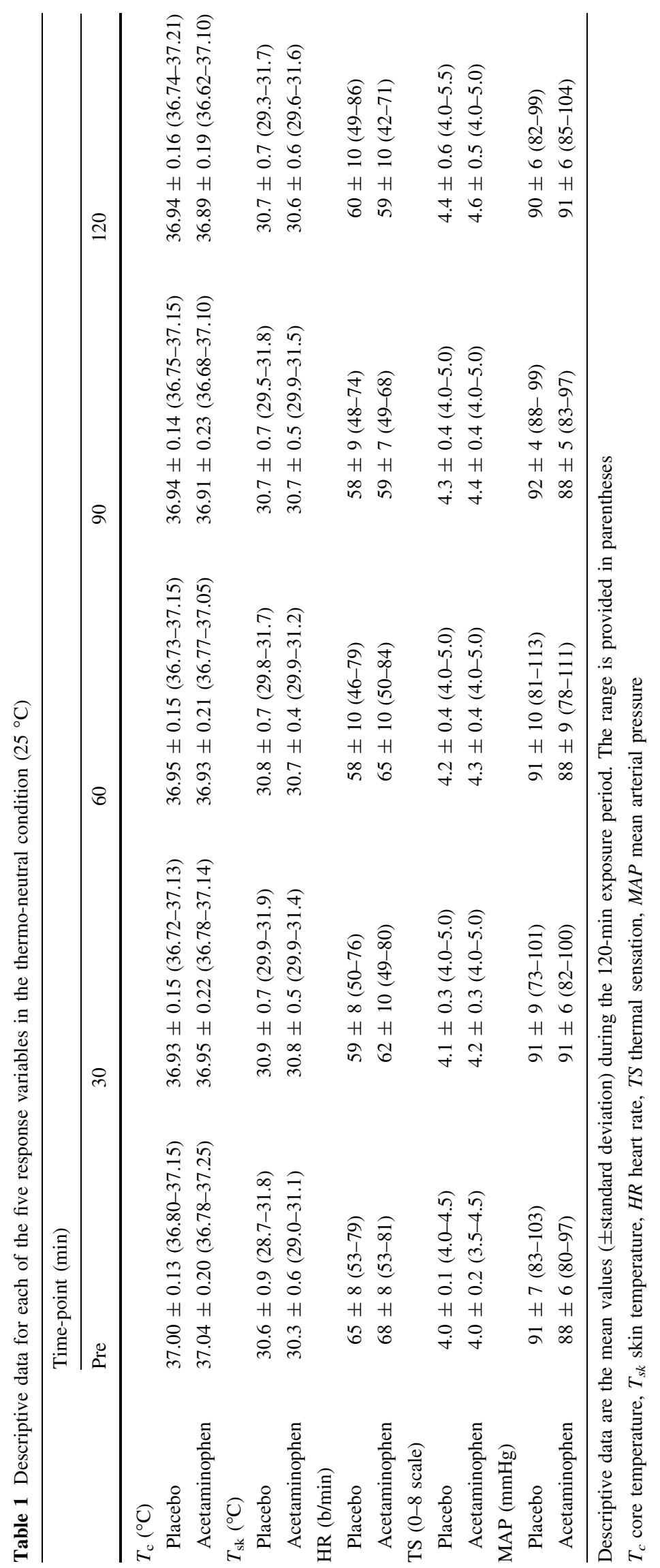




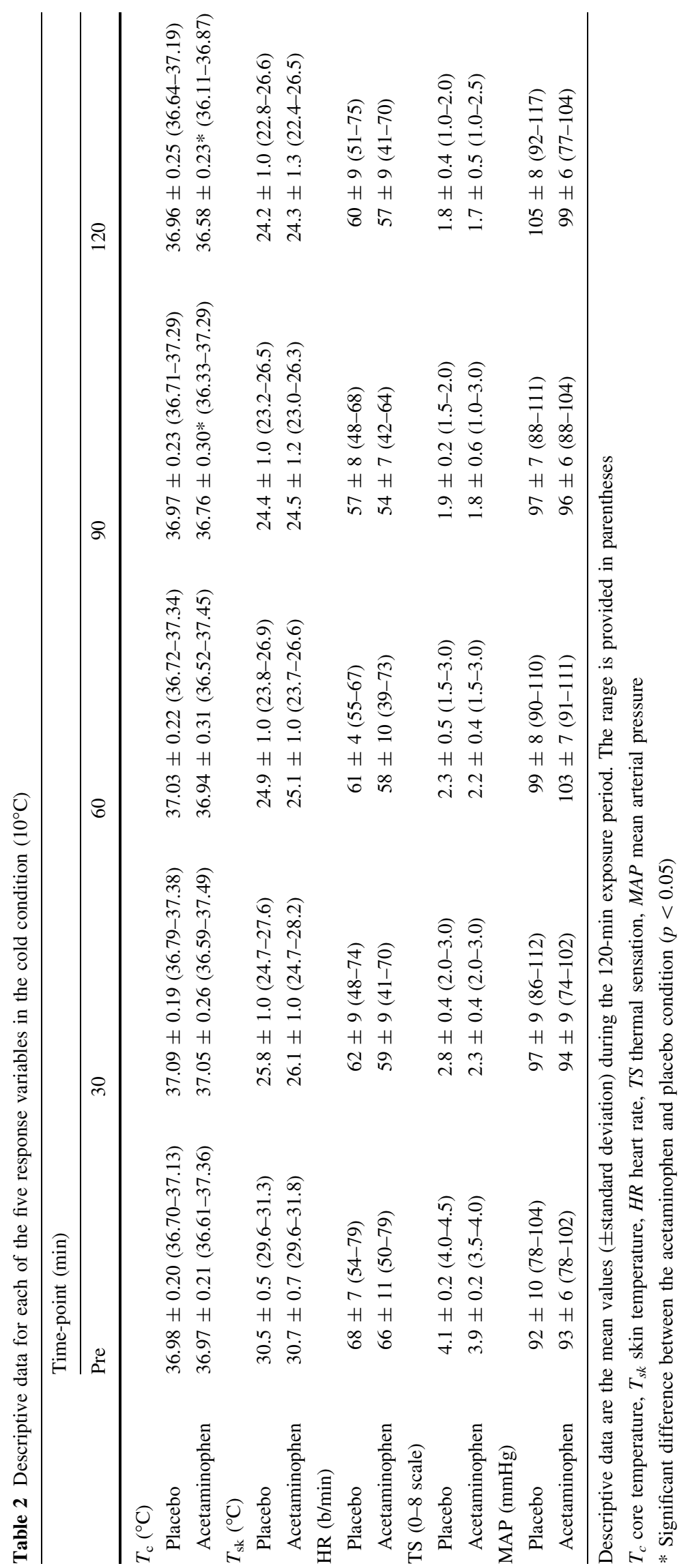




\section{Results}

\subsection{Thermo-neutral}

There was no main effect for drug or interaction effect (drug $\times$ time) for $T_{\mathrm{c}}, T_{\mathrm{sk}}$, heart rate, TSS, or MAP. A main effect for time was present in each of these variables apart from MAP, showing that $T_{\mathrm{c}}, T_{\mathrm{sk}}$, heart rate and TSS changed $(p<0.05)$ over time with no differences observed between acetaminophen and placebo. Descriptive (mean $\pm \mathrm{SD}$ ) data for each 30-min interval is shown in Table 1.

\subsection{Cold}

The $T_{\mathrm{c}}$ response during cold exposure differed between the acetaminophen and placebo conditions. An interaction effect $\left(F_{1,12}=2.25, p=0.01\right)$, main effect for $\operatorname{drug}\left(F_{1,2}=2.25\right.$, $p<0.01)$, and main effect for time $\left(F_{1,12}=8.33, p<0.01\right)$ was found between placebo $\left(37.06 \pm 0.20{ }^{\circ} \mathrm{C} ; 95 \% \mathrm{CI}\right.$ $\left.36.99-37.12{ }^{\circ} \mathrm{C}\right)$ and acetaminophen $\left(36.90 \pm 0.32{ }^{\circ} \mathrm{C}\right.$; $95 \%$ CI $36.79-37.01{ }^{\circ} \mathrm{C}$ ). Specifically, $T_{\mathrm{c}}$ was $0.18,0.19$, $0.22,0.27,0.29$ and $0.35{ }^{\circ} \mathrm{C}$ lower in the acetaminophen trial at time points 70-120 min compared with the placebo. The peak $T_{\mathrm{c}}$ reduction in the nine participants (120-min compared with baseline) was $0.16-0.57{ }^{\circ} \mathrm{C} \quad$ (mean $=$ $\left.0.40 \pm 0.15{ }^{\circ} \mathrm{C}\right)$. Mean and individual $T_{\mathrm{c}}$ responses over the 120-min exposure period are displayed in Figs. 2 and 3, respectively.

There were no main effects for drug or interaction effect between drug and time for $T_{\mathrm{sk}}$, heart rate, TSS, or MAP. A main effect for time was present in each of these variables excluding MAP. All descriptive data for each 30-min interval is shown in Table 2. For $T_{\mathrm{c}}$, Table 3 displays the model's fixed effects coefficients and random effect variances.

\section{Discussion}

It was hypothesised that acetaminophen would reduce $T_{\mathrm{c}}$ in cold conditions, but have no effect on $T_{\mathrm{c}}$ in thermo-neutral conditions relative to a placebo. The experimental hypothesis was accepted. The major finding of the present study was that, compared with a placebo, acetaminophen administration reduced $T_{\mathrm{c}}\left(0.16-0.57{ }^{\circ} \mathrm{C}\right.$ decrease after $120 \mathrm{~min}$ exposure) during an acute cold stress $\left(10^{\circ} \mathrm{C}\right)$, while it appeared to have no effect on thermoregulation at a thermoneutral ambient temperature $\left(25^{\circ} \mathrm{C}\right)$. During cold exposure, acetaminophen caused $T_{\mathrm{c}}$ to fall by $\sim 0.40{ }^{\circ} \mathrm{C}$ compared with the baseline value at $120 \mathrm{~min}$, while it did not decline in the placebo trial. The variability in the response may be due to between-subject differences in the rate of acetaminophen absorption, but unfortunately this was not analysed in this trial. The hypothermic response to acetaminophen ingestion observed in the current study corroborates our prior work in humans, in which acetaminophen reduced $T_{\mathrm{c}}$ by $\sim 0.19{ }^{\circ} \mathrm{C}$ in humans exposed to mild cooling [13]. Furthermore, this is the first study to demonstrate that the ambient temperature can dictate the degree of hypothermia induced by acetaminophen. During cold exposure, this trial shows that healthy young adults could not defend their $T_{\mathrm{c}}$ following acetaminophen administration (Fig. 2). Given that elderly individuals already struggle to defend their $T_{\mathrm{c}}$ without prior drug ingestion [20], it is reasonable to suspect that acetaminophen would cause $T_{\mathrm{c}}$ to decline at a faster rate, increasing the risk of accidental hypothermia.

The notion that ambient and skin temperature dictates the magnitude of acetaminophen's hypothermic action is in line with previous research. In a recent experiment, acetaminophen $(20 \mathrm{mg} / \mathrm{kg})$ had no effect on sweat output and $T_{\mathrm{c}}$ during 1-h exercise in hot conditions $\left(34{ }^{\circ} \mathrm{C}, 52 \% \mathrm{RH}\right)$ at a fixed rate of heat production $(8 \mathrm{~W} / \mathrm{kg})$ [30]. In that study, the mean skin temperature increased by $1{ }^{\circ} \mathrm{C}$ during the trial (up to $\sim 35^{\circ} \mathrm{C}$ ), a condition in which no heatproducing mechanisms will be active [31, 32]. Because the mean skin temperature during cold stress was $\sim 24^{\circ} \mathrm{C}$ at the end of the trial (Fig. 2), cutaneous vasoconstriction and active thermogenesis were required for $T_{\mathrm{c}}$ to remain stable $[33,34]$. The presence of thermogenesis and vasoconstriction indicates that acetaminophen may reduce $T_{\mathrm{c}}$ through inhibition of at least one of these mechanisms, but the precise mechanism needs to be confirmed in future work. Previous data demonstrated that acetaminophen reduced $T_{\mathrm{c}}$ by $0.10-0.39^{\circ} \mathrm{C}$ (mean $\pm \mathrm{SD}, 0.19 \pm 0.09^{\circ} \mathrm{C}$ ) at rest when the mean skin temperature was $\sim 27^{\circ} \mathrm{C}$ [13]. Similar reductions in skin temperature induce shivering thermogenesis [33], which, if inhibited by acetaminophen, may explain the small reduction in $T_{\mathrm{c}}$ seen previously [13].

Studies in mice have shown $T_{\mathrm{c}}$ fell by $0.40,0.80$, and $2{ }^{\circ} \mathrm{C}$ following 1-h acetaminophen infusion of 100, 200, and $300 \mathrm{mg} / \mathrm{kg}$ body mass, respectively [14]. Thus, acetaminophen-induced hypothermia is not only dependent on ambient temperature, but also on the dose administered. It is important to note here that mice are often housed in environments of $18-20{ }^{\circ} \mathrm{C}$, which is $8-10{ }^{\circ} \mathrm{C}$ beneath their normal thermo-neutral zone [35]. These housing conditions are consistent in experiments concerning acetaminopheninduced hypothermia in rodents $[6,8,14]$, such that these animals constantly produce heat to maintain their $T_{\mathrm{c}}$. Inhibition of this heat production through acetaminophen may explain its hypothermic action, a notion that should be confirmed through the administration of high-dose acetaminophen in mice housed within and below their thermoneutral zone (i.e. 30 and $20{ }^{\circ} \mathrm{C}$, respectively). 

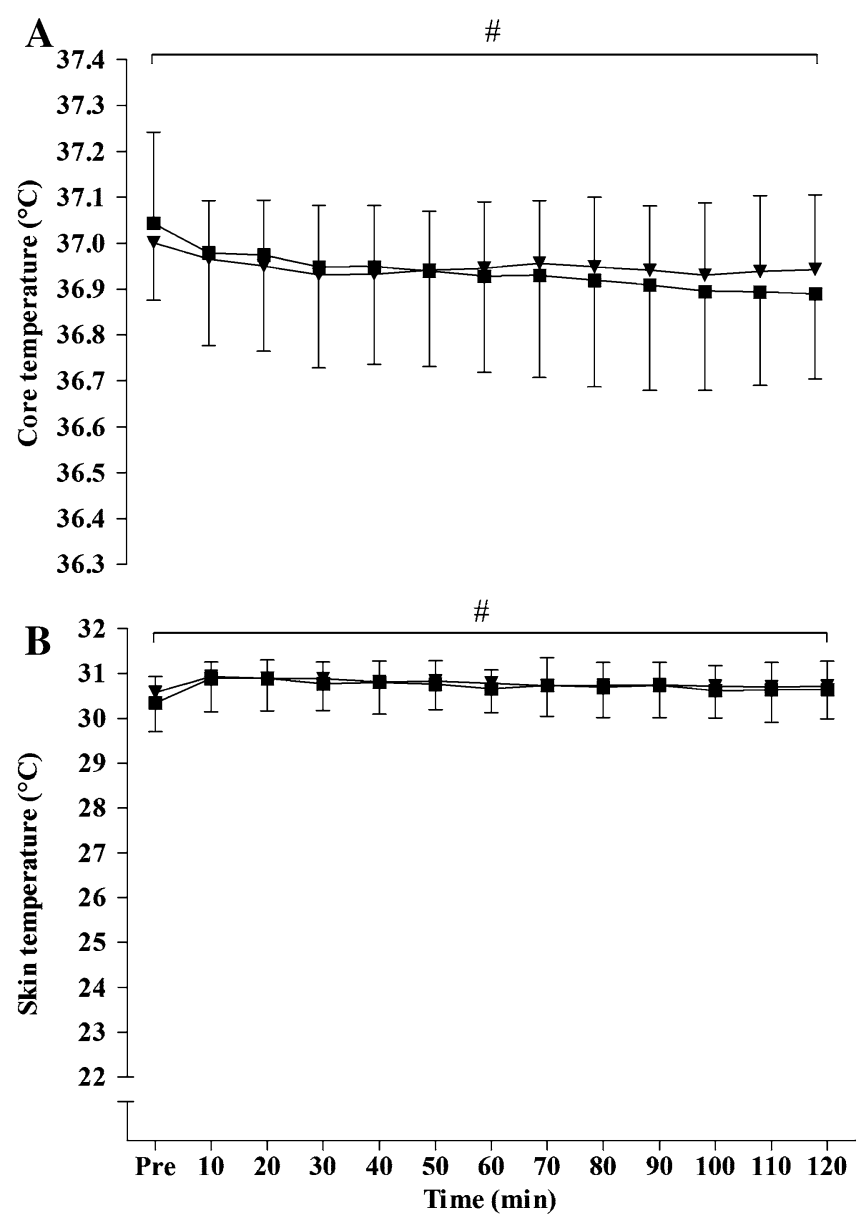

Fig. 2 Mean and SD of the $T_{\mathrm{c}}(\mathbf{a}, \mathbf{c})$ and $T_{\mathrm{sk}}(\mathbf{b}, \mathbf{d})$ response during the 120-min exposure to $25^{\circ} \mathrm{C}$ (left panel, i.e. a, b) and $10{ }^{\circ} \mathrm{C}$ (right panel, i.e. c, d). The triangles and squares represent the placebo and acetaminophen trials, respectively. *Main effect for condition. ${ }^{*}$ Main

It is possible that the acetaminophen-induced reduction in $T_{\mathrm{c}}$ observed in the present study was due to inhibition of cyclooxygenase (COX). There are two COX isoforms (COX-1 and -2), and their function is to convert arachidonic acid to prostaglandin (PG) $\mathrm{H}_{2}$ [36], which cellspecific isomerases and synthases then convert to prostanoids $\left[\left(\mathrm{PGE}_{2}, \mathrm{PGF}_{2}, \mathrm{PGD}_{2}, \mathrm{PGI}_{2}\right)\right.$, and thromboxane $\mathrm{A}_{2}$ $\left.\left(\mathrm{TXA}_{2}\right)\right]$. The strongest evidence that acetaminophen-induced hypothermia is mediated through COX inhibition was provided by Ayoub et al. [14], who demonstrated that acetaminophen reduced $T_{\mathrm{c}}$ by $4{ }^{\circ} \mathrm{C}$ in wild-type mice, but by only $1.5^{\circ} \mathrm{C}$ in a $\mathrm{COX}-1^{-/-}$strain. In addition, they showed a strong relationship between brain $\mathrm{PGE}_{2}$ concentrations and $T_{\mathrm{c}}$, where the maximum reduction in $T_{\mathrm{c}}$ was met with a $96 \%$ reduction in brain $\mathrm{PGE}_{2}$. Data supporting a role for a COX-1 splice variant (COX-1b) in the hypothermic effect of acetaminophen is equivocal. While infusion of putative COX-1b inhibitors aminopyrene and antipyrine exert a similar hypothermic effect to acetaminophen [14, 37], genetic studies suggest that the human
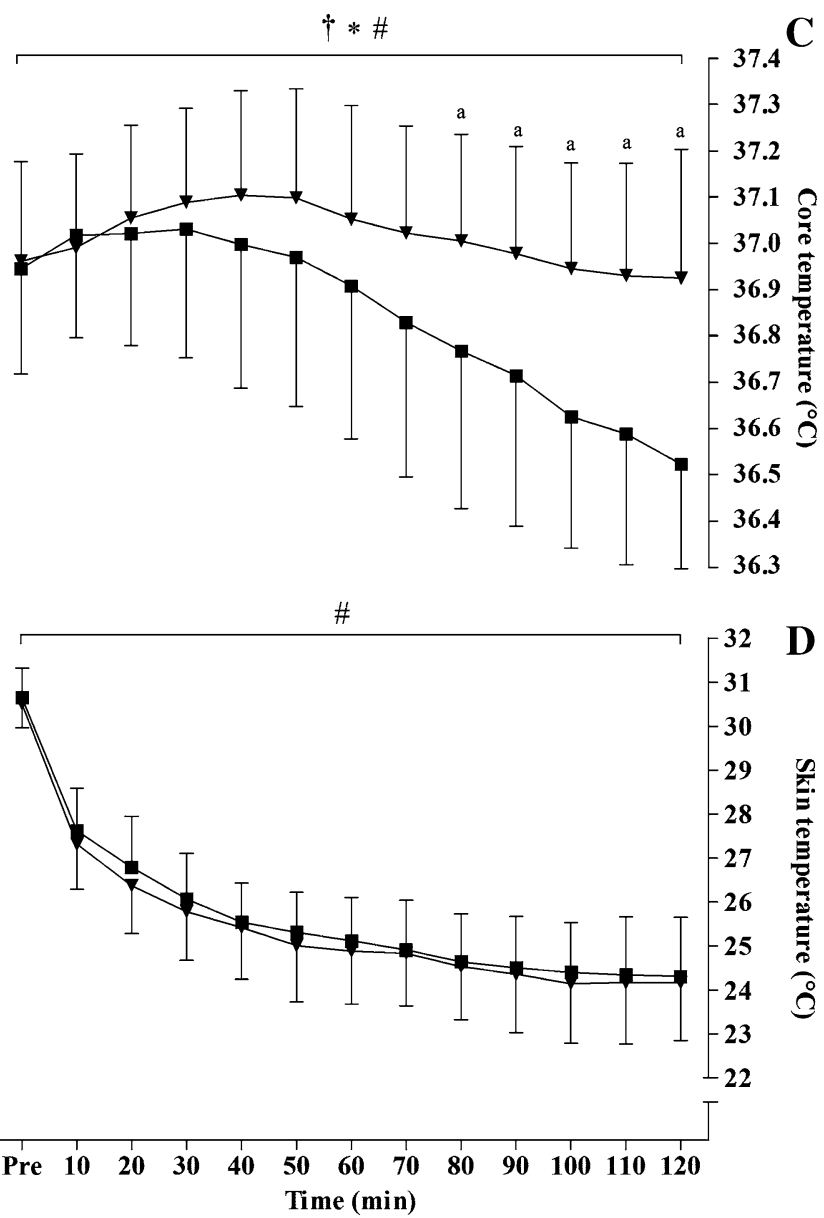

D

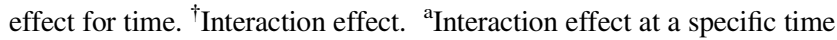
point. Significance set at $p<0.05$. $T_{\mathrm{c}}$ core temperature, $T_{\mathrm{sk}}$ skin temperature

$C O X-1 b$ gene produces a non-functional protein because it retains intron-1 [38]. Even when this was corrected via sitedirected mutagenesis, acetaminophen did not inhibit COX$1 \mathrm{~b}$ activity [39]. Taken together, these studies suggest that COX-1-mediated $\mathrm{PGE}_{2}$ production may be required for normal $T_{\mathrm{c}}$ maintenance in mammals housed in sub-neutral ambient temperatures, while COX-1b is unlikely to be involved. If this were true, similar hypothermic responses would be expected with non-selective COX inhibitors Ibuprofen and Aspirin, or SC-560, a COX-1-specific inhibitor. Whether these drugs initiate a loss of $T_{\mathrm{c}}$ control during cold exposure has not yet been determined.

Given acetaminophen reduced $T_{\mathrm{c}}$ stability in healthy adult males (Fig. 2), its hypothermic effect is likely to be larger in populations already considered vulnerable in subneutral ambient temperatures (i.e. the very young and the elderly). Accidental hypothermia is a rising global health concern. In the USA, the Centre for Disease Control and Prevention report that hypothermia was the cause of nearly 17,000 deaths from 1999 to 2011 [40]. In the UK, hospital 


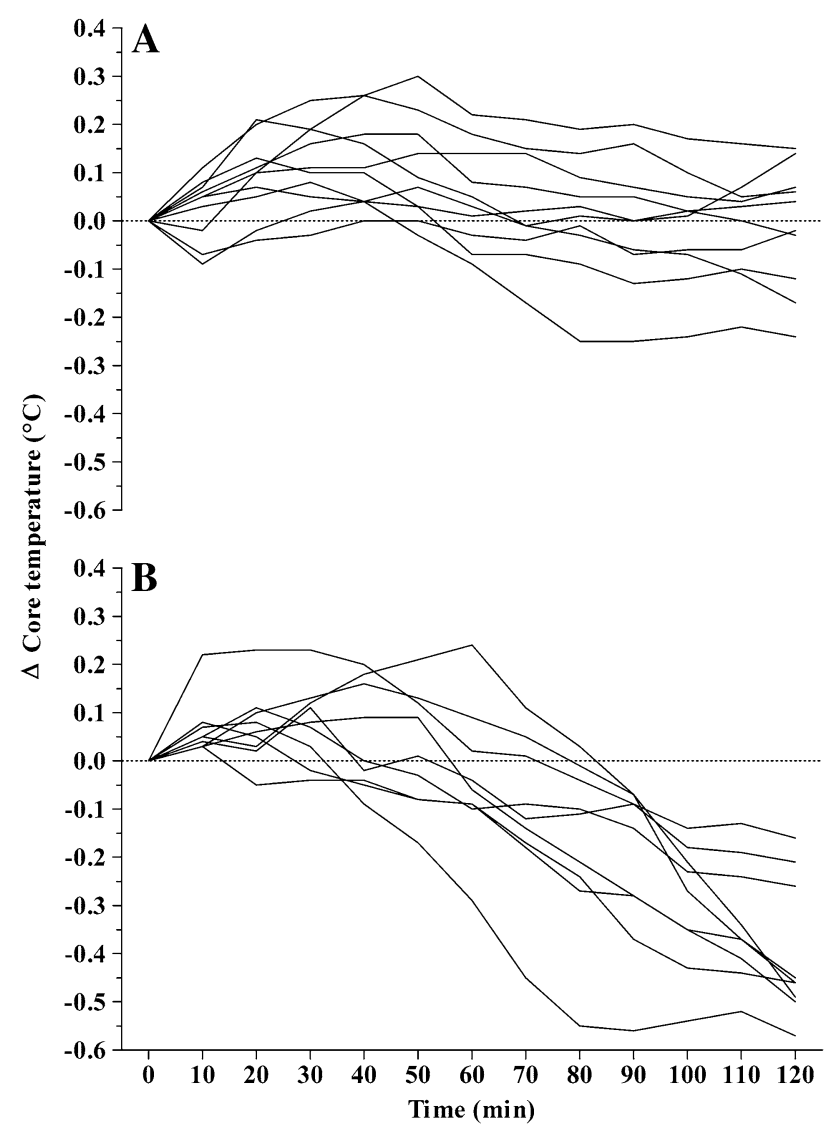

Fig. 3 Change in $T_{\mathrm{c}}$ during cold exposure in each participant following administration of a placebo (a) or acetaminophen (b). $T_{\mathrm{c}}$ core temperature

episode statistics show that there were over 108,000 admissions to NHS hospitals from 2005 to 2014, where hypothermia was the primary or secondary cause [4]. This database also shows that the very young $(0-4$ years; 43,868 admissions) and the elderly ( $\geq 65$ years; 48,477 admissions) make up $85 \%$ of the total admissions. This is concerning for two reasons. First, acetaminophen is the most frequently administered analgesic among frail and pre-frail elderly individuals [41], with no age-related delay in drug absorption [42]. Second, acetaminophen is commonly used for neonatal pain management [43]. In the perioperative setting, $T_{\mathrm{c}}$ monitoring after acetaminophen administration in these vulnerable groups is recommended. A 2011 study showed that intravenous acetaminophen $(\sim 20 \mathrm{mg} / \mathrm{kg})$ did not cause hypothermia in 93 neonates [44]. However, the ambient temperature was not reported (presumably $23-25{ }^{\circ} \mathrm{C}$ ), and only the skin temperature was measured. This is problematic since our work showed a clear reduction in $T_{\mathrm{c}}$ without a change in skin temperature between acetaminophen and placebo [13]. Moreover, neonates are exposed to cold stress when wet with amniotic fluid, during transportation, or during surgery. Based on our data, we
Table 3 Beta coefficients (B), 95\% confidence intervals (CI), alpha values $(p)$, and the Phi coefficient are reported for the fixed components (drug and time) during exposure to cold stress $\left(10^{\circ} \mathrm{C}\right)$

\begin{tabular}{|c|c|c|c|}
\hline & \multicolumn{3}{|c|}{ Core temperature $\left({ }^{\circ} \mathrm{C}\right)$} \\
\hline & $B$ & CI & $p$ \\
\hline \multicolumn{4}{|l|}{ Fixed parts } \\
\hline Intercept & 36.95 & 36.71 to 37.13 & $<0.001$ \\
\hline \multicolumn{4}{|c|}{ Drug $\times$ time interaction } \\
\hline DRUG:TIME10 & 0.03 & -0.11 to 0.17 & 0.694 \\
\hline DRUG:TIME20 & -0.03 & -0.17 to 0.11 & 0.672 \\
\hline DRUG:TIME30 & -0.06 & -0.20 to 0.09 & 0.442 \\
\hline DRUG:TIME40 & -0.10 & -0.24 to 0.04 & 0.179 \\
\hline DRUG:TIME50 & -0.12 & -0.26 to 0.02 & 0.109 \\
\hline DRUG:TIME60 & -0.13 & -0.28 to 0.01 & 0.076 \\
\hline DRUG:TIME70 & -0.18 & -0.32 to -0.03 & 0.021 \\
\hline DRUG:TIME80 & -0.21 & -0.36 to -0.07 & 0.006 \\
\hline DRUG:TIME90 & -0.24 & -0.38 to -0.10 & 0.002 \\
\hline DRUG:TIME100 & -0.29 & -0.43 to -0.15 & $<0.001$ \\
\hline DRUG:TIME110 & -0.31 & -0.45 to -0.17 & $<0.001$ \\
\hline DRUG:TIME120 & -0.36 & -0.50 to -0.22 & $<0.001$ \\
\hline \multicolumn{4}{|l|}{ Phi coefficient } \\
\hline \multicolumn{4}{|l|}{0.938} \\
\hline \multicolumn{4}{|c|}{ Random parts (subject ID) } \\
\hline & Standar & & \\
\hline Intercept & 0.13 & & \\
\hline Residual & 0.16 & & \\
\hline
\end{tabular}

Bold values indicate a signifcant interaction effect between DRUG and TIME $(p<0.05)$

The standard deviation of the intercept and residual are reported for the random effect (subject ID)

propose that acetaminophen may increase the risk of neonatal hypothermia only when coupled with one of these cold stressors, and not in a thermo-neutral environment.

\subsection{Limitations}

This study has limitations that should be considered in future work. First, we did not measure metabolic heat production or cutaneous blood flow, key parameters that control $T_{\mathrm{c}}$ during cold stress. Although a reduction in $T_{\mathrm{c}}$ from resting value is the primary variable of interest from a medical standpoint, it is still unknown what aspect of the thermoregulatory system acetaminophen targets to exert this effect. Measuring metabolic heat production and changes in cutaneous blood flow in future studies of a similar design may help to elucidate the mechanism that regulates acetaminophen's hypothermic action. Second, no pharmacokinetic parameters are reported in this experiment. Disparity in the plasma concentration of 
acetaminophen throughout each trial may have explained the between-subject variability in the hypothermic response elicited by acetaminophen, i.e. a low plasma concentration may result in a reduced hypothermic response. We administered a dose relative to lean body mass to reduce the variability in acetaminophen absorption, and our previous experiment showed that a $20 \mathrm{mg} / \mathrm{kg}$ lean body mass dose was appropriate for therapeutic plasma concentrations to be reached within the 120-min exposure period [13].

\section{Conclusions}

In conclusion, this preliminary trial demonstrated that acute acetaminophen ingestion $(20 \mathrm{mg} / \mathrm{kg}$ lean body mass) reduced $T_{\mathrm{c}}$ maintenance during acute cold exposure in healthy young adults. We are the first to show that the hypothermic action of acetaminophen is strongly influenced by the ambient temperature in which it is administered. Future research should determine if this effect is amplified in new-borns and in elderly individuals, placing them at risk of accidental hypothermia. It should also be determined if hypothermic effects are limited to acetaminophen, or are present in COX inhibitors such as Ibuprofen and Aspirin (non-selective COX inhibitors), or COXIBs (COX-2 selective inhibitors). If all COX inhibitors induce hypothermia during cold exposure, the prescription of these medications to individuals vulnerable to hypothermia should be carefully considered during cold spells and in the perioperative period.

Acknowledgements The authors thank Miss Katie Thomasson and Mr Jack Field for their assistance with data collection. The authors also thank those who participated in this experiment.

Author Contributions JF, LT, and ARM contributed to the conception and design of the study. JF, LT, DH and AG contributed to data interpretation and manuscript revision. JF collected the data. All authors agree to be accountable for all aspects of the work in ensuring that questions related to the accuracy or integrity of any part of the work are appropriately investigated and resolved. All authors approved the final version of the manuscript and all authors qualifying for authorship are listed.

\section{Compliance with Ethical Standards}

Funding None declared.

Conflict of interests The authors declare they have no competing interests.

\section{References}

1. Brown DJA, Brugger H, Boyd J, Paal P. Accidental hypothermia. N Engl J Med. 2012;367:1930-8.
2. Filippi S, Gizzi A, Cherubini C, Luther S, Fenton FH. Mechanistic insights into hypothermic ventricular fibrillation: the role of temperature and tissue size. Europace. 2014;16:424-34.

3. Berko J, Ingram DD, Saha S, Parker JD. Deaths attributed to heat, cold, and other weather events in the United States, 2006-2010. Natl Health Stat Rep 2014;76:1-15.

4. HSCIC. Hospital episode statistics: admitted patient care 2013 to 2014. http://www.hscic.gov.uk/media/15004/Hypothermia-nationalstats-by-age-2005-06-to-2013-14/xls/Hypothermia_national_stats_ by_age_200506_to_201314.xlsx.

5. Anderson B. Paracetamol (Acetaminophen): mechanisms of action. Pediatr Anesth. 2008;18:915-21.

6. Ayoub SS, Pryce G, Seed MP, Bolton C, Flower RJ, Baker D. Paracetamol-induced hypothermia is independent of cannabinoids and transient receptor potential vanilloid-1 and is not mediated by AM404. Drug Metab Dispos. 2011;39:1689-95.

7. Walker RM, Massey TE, McElligott TF, Racz WJ. Acetaminophen-induced hypothermia, hepatic congestion, and modification by $\mathrm{N}$-acetylcysteine in mice. Toxicol Appl Pharmacol. 1981;59:500-7.

8. Li S, Dou W, Tang Y, Goorha S, Ballou LR, Blatteis CM. Acetaminophen: antipyretic or hypothermic in mice? In either case, PGHS-1b (COX-3) is irrelevant. Prostaglandins Other Lipid Mediat. 2008;85:89-99.

9. Lindquist M. VigiBase, the WHO global ICSR database system: basic facts. Drug Inf J. 2008;42:409-19.

10. Van Tittelboom T, Govaerts-Lepicard M. Hypothermia: an unusual side effect of paracetamol. Vet Hum Toxicol. 1989;31:57-9.

11. Block R, Jankowski JA, Lacoux P, Pennington CR. Does hypothermia protect against the development of hepatitis in paracetamol overdose? Anaesthesia. 1992;47:789-91.

12. Rollstin AD, Seifert SA. Acetaminophen/diphenhydramine overdose in profound hypothermia. Clin Toxicol (Phila). 2013;51:50-3.

13. Foster J, Mauger A, Thomasson K, White S, Taylor L. Effect of acetaminophen ingestion on thermoregulation of normothermic, non-febrile humans. Front Pharmacol. 2016;7:54.

14. Ayoub SS, Botting RM, Goorha S, Colville-Nash PR, Willoughby DA, Ballou LR. Acetaminophen-induced hypothermia in mice is mediated by a prostaglandin endoperoxide synthase 1 gene-derived protein. Proc Natl Acad Sci. 2004;101:11165-9.

15. Foster J, Mauger AR, Chrismas BCR, Thomasson K, Taylor L. Is prostaglandin E2 (PGE2) involved in the thermogenic response to environmental cooling in healthy humans? Med Hypotheses. 2015;85:607-11.

16. Blieden M, Paramore LC, Shah D, Ben-Joseph R. A perspective on the epidemiology of acetaminophen exposure and toxicity in the United States. Expert Rev Clin Pharmacol. 2014;7:341-8.

17. Hochberg MC, Altman RD, April KT, et al. American College of Rheumatology 2012 recommendations for the use of nonpharmacologic and pharmacologic therapies in osteoarthritis of the hand, hip, and knee. Arthritis Care Res (Hoboken). 2012;64:465-74.

18. Hall RW, Shbarou RM. Drugs of choice for sedation and analgesia in the neonatal ICU. Clin Perinatol. 2009;36:15-26.

19. Ohlsson A, Shah PS. Paracetamol (acetaminophen) for prevention or treatment of pain in newborns. Cochrane Database Syst. Rev. 2016;10:CD011219.

20. Collins K. Hypothermia: the elderly person's enemy. Practitioner. 1995;239:22-6.

21. Onalo R. Neonatal hypothermia in sub-Saharan Africa: a review. Niger J Clin Pract. 2013;16:129-38.

22. Dippel DWJ, van Breda EJ, van der Worp HB, et al. Timing of the effect of acetaminophen on body temperature in patients with acute ischemic stroke. Neurology. 2003;61:677-9.

23. Saunders JB, Aasland OG, Babor TF, de la Fuente JR, Grant M. Development of the alcohol use disorders identification test (AUDIT): WHO collaborative project on early detection of 
persons with harmful alcohol consumption-II. Addiction. 1993;88:791-804.

24. Kwo PY, Ramchandani VA, O'Connor S, et al. Gender differences in alcohol metabolism: relationship to liver volume and effect of adjusting for body mass. Gastroenterology. 1998;115:1552-7.

25. Blondin DP, Labbé SM, Tingelstad HC, et al. Increased brown adipose tissue oxidative capacity in cold-acclimated humans. J Clin Endocrinol Metab. 2014;99:E438-46.

26. Poirier MP, Gagnon D, Friesen BJ, Hardcastle SG, Kenny GP. Whole-body heat exchange during heat acclimation and its decay. Med Sci Sports Exerc. 2015;47:390-400.

27. Ramanathan NL. A new weighting system for mean surface temperature of the human body. J Appl Physiol. 1964;19:531-3.

28. Causton D, Grafen A, Hails R. Modern statistics for the life sciences. Ann Bot. 2002;90:776-7.

29. Akaike H. Maximum likelihood identification of Gaussian autoregressive moving average models. Biometrika. 1973;60:255.

30. Coombs GB, Cramer MN, Ravanelli NM, Morris NB, Jay O. Acute acetaminophen ingestion does not alter core temperature or sweating during exercise in hot-humid conditions. Scand J Med Sci Sports. 2015;25:96-103.

31. Nakamura K, Morrison SF. A thermosensory pathway mediating heat-defense responses. Proc Natl Acad Sci. 2010;107:8848-53.

32. Nakamura K, Morrison SF. Central efferent pathways for colddefensive and febrile shivering. J Physiol. 2011;589:3641-58.

33. Gosselin C, Haman F. Effects of green tea extracts on nonshivering thermogenesis during mild cold exposure in young men. Br J Nutr. 2013;110:282-8.

34. Haman F, Legault SR, Rakobowchuk M, Ducharme MB, Weber J-M. Effects of carbohydrate availability on sustained shivering II. Relating muscle recruitment to fuel selection. J Appl Physiol. 2003;96:41-9.
35. Speakman JR, Keijer J. Not so hot: optimal housing temperatures for mice to mimic the thermal environment of humans. Mol Metab. 2013;2:5-9.

36. Simmons DL, Botting RM, Hla T. Cyclooxygenase isozymes: the biology of prostaglandin synthesis and inhibition. Pharmacol Rev. 2004;56:387-437.

37. Chandrasekharan NV, Dai H, Roos KLT, et al. COX-3, a cyclooxygenase-1 variant inhibited by acetaminophen and other analgesic/antipyretic drugs: cloning, structure, and expression. Proc Natl Acad Sci. 2002;99:13926-31.

38. Dinchuk JE, Liu RQ, Trzaskos JM. COX-3: in the wrong frame in mind. Immunol Lett. 2003;86:121.

39. Censarek P, Freidel K, Hohlfeld T, Schrör K, Weber A-A. Human cyclooxygenase- $1 \mathrm{~b}$ is not the elusive target of acetaminophen. Eur J Pharmacol. 2006;551:50-3.

40. Centers for Disease Control and Prevention (CDC) U. Hypothermia-related deaths-United States, 1999-2002 and 2005. MMWR Morb Mortal Wkly Rep. 2006;55:282-4.

41. Koponen MPH, Bell JS, Karttunen NM, Nykänen IA, Desplenter FAM, Hartikainen SA. Analgesic use and frailty among community-dwelling older people: a population-based study. Drugs Aging. 2013;30:129-36.

42. Divoll M, Ameer B, Abernethy DR, Greenblatt DJ. Age does not alter acetaminophen absorption. J Am Geriatr Soc. 1982;30: $240-4$.

43. Allegaert K, van den Anker JN. Neonatal pain management: still in search for the Holy Grail. Int $\mathrm{J}$ Clin Pharmacol Ther. 2016;54:514-23.

44. Hopchet L, Kulo A, Rayyan M, et al. Does intravenous paracetamol administration affect body temperature in neonates? Arch Dis Child. 2011;96:301-4. 